\title{
A case study on methodological pluralism in public health research in Africa
}

This article was published in the following Dove Press journal:

Research and Reports in Tropical Medicine

2I September 2010

Number of times this article has been viewed

\section{Valéry Ridde ${ }^{1,2,3}$}

'Research Centre of the University of Montreal Hospital Centre (CRCHUM), Canada; ${ }^{2}$ Department of Social and Preventive Medicine, University of Montréal, Canada; ${ }^{3}$ Institut de Recherche en Science de la Santé (IRSS) du CNRST, Burkina Faso
Correspondence: Valéry Ridde Unité de santé internationale. 3875 St-Urbain, 5th floor (507); Montréal, QC; H2 W IVI Canada $\mathrm{Tel}+\mathrm{I} 5 \mathrm{I} 48908125$

Fax +I 5I4 4I2 7I08

Email valery.ridde@umontreal.ca

\begin{abstract}
Like the field of medicine from which it emanates, public health is more a process of intervention than a research activity. As such, the premise of this empirical article is that public health is not a science. The corollary to this is that studies in public health must draw upon many scientific disciplines and must therefore employ a methodological pluralism, given the complexity of the subjects under study. To illustrate this view, we analyzed a posteriori, in the manner in which we carried out a doctoral research study on a development health policy implementation gap in Burkina Faso. We based this analysis on Yin's suggestion that the more pluralism is used in each research procedure during the whole research process, the more the study could be labeled pluralist. The present article demonstrates our attempts to be as integrative as possible and to use pluralism at every step. We used an embedded design in which quantitative data play a supportive, secondary role in a study based primarily on qualitative data, such that the design could be summarized as QUAL (quan). Methodological pluralism appears primordial in public heath and development research, and the academic world must adapt to this requirement, particularly in terms of training students in interdisciplinary and mixed methods approaches.
\end{abstract}

Keywords: pluralism, public health, Burkina Faso

\section{Introduction}

Like the field of medicine from which it emanates, public health is more a process of intervention than a research activity giving scientific knowledge. This does not mean there is no public health research, ie, research on or for the improvement of public health interventions. ${ }^{1}$ However, the starting point for this article is that public health is not a science. It might be said that public health actions, like all social activity, produce knowledge, which could constitute a definition as science. Nevertheless, this knowledge that is elicited and brought to light in the course of interventions appears mostly practical and tacit (lay knowledge) rather than scientific and theoretical. For our purpose, the definition we retain proposes that science essentially aims to understand and explain phenomena, ${ }^{2}$ ie, to "work toward clarity" as Weber said. ${ }^{3}$ Public health aims to act and to produce changes beneficial to the health of populations. ${ }^{a}$ Of course, as with science, the definition of public health has been the subject of debates for decades. The definition most often taken up in textbooks, and adopted in 1952 by WHO, dates from the early 20th century, when Winslow asserted that public health is a science and an art of preventing illness, prolonging life and promoting the health of populations, ${ }^{5,6}$ as opposed to medicine, which looks after the health of individuals. This dual nature (cognition vs action)

${ }^{a}$ And less often, unfortunately, to reduce the social inequalities in health. ${ }^{4}$ 
positions public health in both the realms of research and scientific knowledge, and of intervention and tacit or pragmatic knowledge. However, it is important to recognize that issues of definition are central to the history of science and to the creation of scientific disciplines. Just like their colleagues working in the field of program evaluation, ${ }^{7,8}$ academic researchers in public health must construct their young discipline and build up its (and their) legitimacy. While the practice of public health dates back very far in time, ${ }^{9}$ public health research is still quite recent and is nearly absent in some countries. After all, if public health becomes a scientific discipline by setting aside its "artistic" dimension - referring back to Winslow's definition - it can claim a university department, research grants, professorships, scientific journals, etc. This happens in some countries, but worldwide this is the exception rather than the norm. We therefore start from the position that public health is more a mode of intervention than a science.

While public health actions have a long history of implementation, it is only very recently that, when planning actions or intervening, public health actors have turned to science to understand the situations in which they wish to act or to explain their success. This new attitude toward science has developed mostly because of the demand for evidence-based public health. When public health actors turn to science, they call upon a myriad of scientific disciplines: "The basic sciences of public health are epidemiology and biostatistics, but their effective use depends in turn on the knowledge and strategies derived from the biological, physical, social, and demographic sciences". ${ }^{10}$ This quotation, drawn from one of the more well-known textbooks, demonstrates the positivist and quantitative origin of public health research (the dominant force, according to McKinlay and Marceau) ${ }^{11}$ and provides an opening into other scientific disciplines. In fact, while public health derives from medicine and a certain vision of science (and causal relationships between factors and illness), the thinking on these has evolved considerably. Today public health discourse speaks less about illness and more about health, less about individual behaviors and more about socio-political determinants, less about public health and more about health promotion, and less about the health of populations and more about social inequalities in health. This evolution towards a greater consideration of complexity remains more theoretical (confined to the research domain) than practical (rarely organized in interventions). For instance, public health researchers suggest studying the contribution of certain factors and not the determinants on the effects of interventions. ${ }^{12}$ Attributing cause is actually a delicate, if not impossible, activity when we are dealing with complex interventions (eg, public health), as compared with "simple" interventions (eg, biomedical). Thus, it seems more prudent to suggest that a factor contributed to an effect, rather than having determined it. One clear reason for this epistemological (r)evolution is that, in contrast to a certain vision of medicine and illness, public health interventions constitute objects that are eminently complex and that act upon objects that are equally complex, which, to understand and explain the effects, requires recourse to methodological pluralism. ${ }^{13}$

The problem with complexity is that it "presents with the worrisome traits of messiness, inextricability, disorderliness, ambiguity, uncertainty...". ${ }^{14}$ We therefore need to mobilize complex thinking based on a plurality of theoretical models, given that public health has been orphaned by such models and that complexity requires plurality. This is even more true because public health research is carried out in the field and is not confined to reliance on the classical dichotomy. ${ }^{15}$ Society and organizations sponsoring research expect the results of these studies to be useful for public health action. Recourse to pluralism is therefore essential: "injurious thought leads inevitably to injurious actions". ${ }^{14}$ Both the field and the subjects of public health research thus become necessarily complex and pluralistic.

Our thesis is that, to deal with the complexity of subjects studied in the field of public health, we must necessarily employ methodological pluralism. Our objective is to illustrate this view by means of an a posteriori analysis of how we carried out a research study on a health policy implementation gap in Burkina Faso (West Africa). A growing number of authors favour using methodological pluralism. ${ }^{16-18}$ However, while there are empirical articles that present results coming out of methodological pluralism, articles providing detail on methodology and processes are rare. Aside from a few case studies available only since 2007 in two textbooks ${ }^{16,17}$ and two new journals, ${ }^{b}$ students and researchers have no examples to guide them in undertaking this type of innovation. Such is the objective of this article, in response to an expressed need: "one important approach is to publicize and carefully examine existing exemplars of such work". ${ }^{19}$

\section{Methodological pluralism}

As we review the literature on methodological pluralism, we become aware at once of the diversity of perspectives and the multitude of terms used by authors. Borrowing from Patton's terminology ${ }^{20}$ regarding the field of evaluation, we are

'International Journal of Multiple Research Approaches; Journal of Mixed Methods Research. ${ }^{4}$ 
confronted with a veritable "alphabet soup" that has grown up in recent years with the arrival of the scene of the mixed methods concept (Figure $1^{16,21,22}$ ). We will not attempt to distinguish among these terms - if that were even possible since that is beyond the scope of this paper. Our more modest goal has been to carry out a case study that will demonstrate the importance, and the feasibility within the context of a doctoral research study, of applying methodological pluralism in public health research.

The main idea behind methodological pluralism is that knowledge can be accumulated, beyond diverse theories and frameworks, from a variety of sources and in many ways, and that therefore methodological diversity should be embraced. It has been defined as the belief that there is no best approach to research; instead, what is important is that the methods, theories and concepts employed be appropriate for the questions under investigation. ${ }^{23}$ In many cases, the phrase "methodological pluralism" is used simply to describe the employment of multiple methods, concepts and frameworks in a research study, program or discipline. ${ }^{24}$ In accordance with the literature on applied research (evaluation, education, health, nursing, etc.), ${ }^{24-26}$ methodological pluralism has been conflated in the present article with mixed methods research, using Yin's ${ }^{27}$ work (see below) as a platform from which this definition has been applied throughout the research process.

A common justification offered for methodological pluralism is to encourage objectives-driven, rather than methodsdriven, research. The idea is that certain methods, concepts, and frameworks, irrespective of their paradigmatic baggage, may be more appropriate to certain questions than others and often pluralism is needed to understand complex social phenomena. ${ }^{18}$ Special attention is given here to triangulation because this is the most frequently invoked reason for conducting methodological pluralism. ${ }^{25}$ Traditionally, triangulation

Multitrait-multimethod research; integrating qualitative and quantitative approaches; intergated methods; interrelating qualitative and quantitative data; methodological triangulation; multimethodological research; multimethod designs and linking qualitative and quantitative data; multiple methods; combining qualitative and quantitative research; mixed model studies; blended methods; and mixed methods research.

Figure I Alphabet soup of methodological pluralism. refers to the intentional use of multiple methods with offsetting or counteracting biases to investigate the same phenomenon and to strengthen the validity or credibility of inquiry results. ${ }^{28}$ Forty years ago, Denzin extended the idea of triangulation and distinguished four forms: (i) data triangulation, (ii) investigator triangulation, (iii) theoretical triangulation, and (iv) methodological triangulation. It is believed that combining different methods can strengthen a study by producing converging evidence that is presumably more compelling than what might have been produced by one method alone..$^{29}$ One premise behind triangulation is that each method contains its own weaknesses that translate into bias and measurement error Using several methods compensates for these weaknesses by capitalizing on the advantages of each method. The objective of triangulation is not to obtain data that are complementary, but to obtain data that are rather convergent. However, as Greene ${ }^{17}$ notes, triangulation may not necessarily yield convergence, but may instead generate empirical puzzles that warrant future study and contemplation. She welcomes the potential value of divergence and dissonance.

\section{Material and methods}

This paper advocates for methodological pluralism throughout the research process, within a single study. Epistemologically, this case study fits within a constructivist perspective. This perspective assumes that the subjects' knowledge is not the reality, but rather a (re)construction of it, and that we must follow a socially-constructed logic to interpret the reality. An analytical framework that integrates concepts and theories from many disciplines (see below) allows the investigator to formulate several hypotheses and to circumscribe the areas of investigation, as suggested by Huberman and Miles. ${ }^{30}$ These hypotheses must be understood as starting positions - not end points - that help orient empirico-inductive research, rather than as hypotheses to be verified using a positivist hypothetico-deductive approach.

To Yin, ${ }^{27}$ integration across research procedures within a single study is paramount to ensuring that the mixed methods study will not disintegrate into multiple studies. Forcing the use of multiple methods into the confines of a single study avoids the more traditional realm of research synthesis, metaanalyses and other aggregate procedures, in which separate studies are conducted and later synthesized. Recently, it seems many mixed methods researchers have come to define mixed methods as something that occurs within a single study. ${ }^{23,25,31}$ In their handbook, Teddlie and Tashakkori ${ }^{32}$ previously called this type of study as mixed model research, "in which mixing of QUAL and QUAN approaches occurs in all stages of the 
study (formulation of research questions, data collection, procedures and research method, and interpretation of results to make final inferences) or across stages of the study." Currently, they believe most mixed methods research recognizes that a study is not considered mixed if there is no integration across stages, and so they no longer feel a need to distinguish between mixed models and mixed methods studies. ${ }^{31}$ It is more a matter of being "mixed in many or all stages of the study". ${ }^{33}$ Thus, Yin makes the following claim: "the more that a single study integrates mixed methods across the five procedures (ie, research stages), the more that mixed methods research ... is taking place". ${ }^{27}$ The research process can be summarized in six steps, which are also points at which pluralism can be applied: (i) research questions; (ii) conceptual framework and theoretical approach; (iii) sampling; (iv) tools and data collection; (v) data analysis; and (vi) knowledge dissemination and utilization. This last step shows the extent to which research and intervention are often intimately interrelated in the field of public health. The objective of this article is to describe one such process, the study of a case limited in time and space and undertaken within the context of a doctoral thesis defended in 2005. Our wish is to provide a few examples, a posteriori, of how the author of this paper attempted to integrate mixing/ pluralism into different stages of this study.

\section{Results}

Based on an empirical study carried out in a West-African country that was aimed at understanding the implementation gap of a public health policy, ${ }^{34}$ our goal here is to reflect on some elements that demonstrate the importance of methodological pluralism.

\section{Research questions}

With respect to research questions, Yin $^{27}$ suggests that pluralism should be observed in the way in which a single question can be addressed using several methods, rather than just one. He also explains that a single method can be useful in responding to several research questions. The objective of this study undertaken in Burkina Faso was to understand why, during implementation, actors were drawn to health policies solely for their orientation towards effectiveness, thereby neglecting equity aspects. For example, every effort was made to improve access to drugs in health centers, but nothing was implemented to allow the worst-off, the indigent, to obtain these drugs when they did not have the means to pay.

One of our research questions was aimed at understanding emic (ie, insider) perspectives of the concept of equity (social justice) in the social context of this case study. Based on classic works, ${ }^{35,36}$ we hypothesized that the health policy's implementation failure with respect to its equity objective could be explained primarily by the fact that absence of equity was never perceived to be a public issue. To respond to this complex question we used multiple methods: concept mapping $(\mathrm{n}=2$, see below), documentation and archives, socioanthropological observations over a period of 7 months, focus groups $(n=4)$, informal interviews $(n=60)$, and in-depth interviews $(n=22)$. The results show that mass social mobilization for justice is egalitarian in type. Health inequalities or social inequalities are understood by individuals as facts that cannot be acted upon, while inequalities in access to care are qualified as unjust, and it is possible to intervene to reduce them if incentive measures to this effect are taken (Figure 2). Using multiple methods allowed us to better grasp

\section{Disparities}

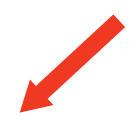

Health services

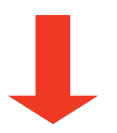

Inequalities

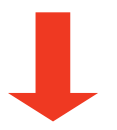

Social Justice

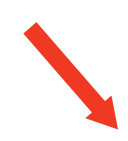

Health and society

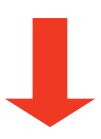

Differences

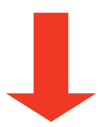

Incitation Facts

Figure 2 Emic perspectives on inequalities and differences. 
the concept of equity in this social context and contributed to explaining the implementation gap.

Lying the technique of participant observation through a 7-month immersion in the study arena is the epitome of the example suggested by Yin of a useful method for collecting data related to several questions. This technique allowed us to understand (in some measure) the concept of equity, to take into consideration the interaction between social actors and the role of power in policy implementation (see below), to observe and understand the absence of the political entrepreneur, etc. - all elements related to several research questions in this study.

\section{Conceptual framework and theoretical approach}

$\mathrm{Yin}^{27}$ suggests that "every study has an implicit if not explicit unit of analysis or assignment". By "unit of analysis", we understand he is referring to the way in which the research subject is approached, that is, the conceptual framework that will guide data collection.

\section{Implementation gap and stream theory}

Because "we are not even close to a well-developed theory of policy implementation", ${ }^{37}$ we decided to innovate by using the extension of the multiple-streams framework ${ }^{35}$ to examine policy implementation. In line with Lemieux's propositions ${ }^{38}$ and Zahariadis' recommendations, ${ }^{39}$ the multiple-streams framework has been shown to be useful for examining policy implementation. Although policy implementation has been studied for thirty years, no one has examined it using Kingdon's framework. ${ }^{40}$ According to Kingdon, ${ }^{35}$ public policies emerge when policy entrepreneurs seize windows of opportunity to couple a problem stream with a political stream. The policy stream is also present, but loosely coupled with the other 2 . Without this coupling, no policy can emerge. Lemieux ${ }^{38}$ extends this interpretation, suggesting that while policy formulation involves coupling the policy and political streams, implementation involves coupling the policy and problem streams. In both cases, the third (ie, politics) stream is present but loosely coupled. Although the scientific relevance and theoretical value of this extension have been demonstrated, ${ }^{38}$ they have only been empirically validated once in Canada. ${ }^{41}$

At the same time, policy analysis can be undertaken by studying a process and the actors who take part in it. In our examination of the implementation gap of a public policy that was largely imported and then implemented by means of aid development projects, we found the "neo-interactionism" theory from development anthropology to be useful for studying the roles of actors. ${ }^{42}$ According to this disciplinary approach, it is important to take stock of the constraints affecting each player and to decipher the strategies they employ. Advocates of this approach consider that actors have room for maneuver and are not dependent solely on social determinants or cultural inertia. Thus, Olivier de Sardan ${ }^{42}$ explains that "beyond an infinite potential variety of individual actions and reactions, we are dealing with a relatively finite number of behaviors". He defines reasoning as "the diverse lines of cohesion that the observer deduces from empirical observation of groups of differential individual practices, without prejudging any theory".

\section{Implementation gap and power}

In addition, Lemieux ${ }^{38}$ tells us that it is through the exercise of power that public policies are, or are not, carried out. In this study, therefore, we looked at the actors' exercise of power, which should be the cornerstone of "all serious analysis of collective action". ${ }^{43}$ The issues concern decisions on resources available to the actors in question, since ultimately, "use of resources is a direct function of intensity of preference". ${ }^{44}$ There are many types of resources, which can be classified, using Lemieux's typology, into seven categories. These categories can then, in line with Crozier and Friedberg, ${ }^{43}$ be considered as positive characteristics of the actors (assets) or aptitudes that can be mobilized (issues). The resources are normative (norms), statutory (positions), actionable (commands), relational (links), material (supports), human (staff), and finally, informational (information). Clearly, in exercising control, several resources can be used at the same time, while on the other hand, the resources of any one actor must be compared with those of the others, since power is always relative. Moreover, resources must be seen as assets that allow various actors to ensure that decisions are taken to suit their own preferences. The interaction among actors and the exposure of their social logic, as proposed by development anthropology, should thus, for heuristic reasons, be studied through an analysis of the issue of power and the social actors' control over resources. We hypothesized that power must be understood as the source and the underlying cause of the emergence of the actors' social logics that we were able to uncover in this study (Figure 3).

Based on careful study of the empirical manifestations of ten recurrent social logics, we attempted to understand which resources were most important in the exercise of power. Broadly speaking, among the resources most at stake at the time of the statements we elicited, three stand out: links, supports, and positions. 


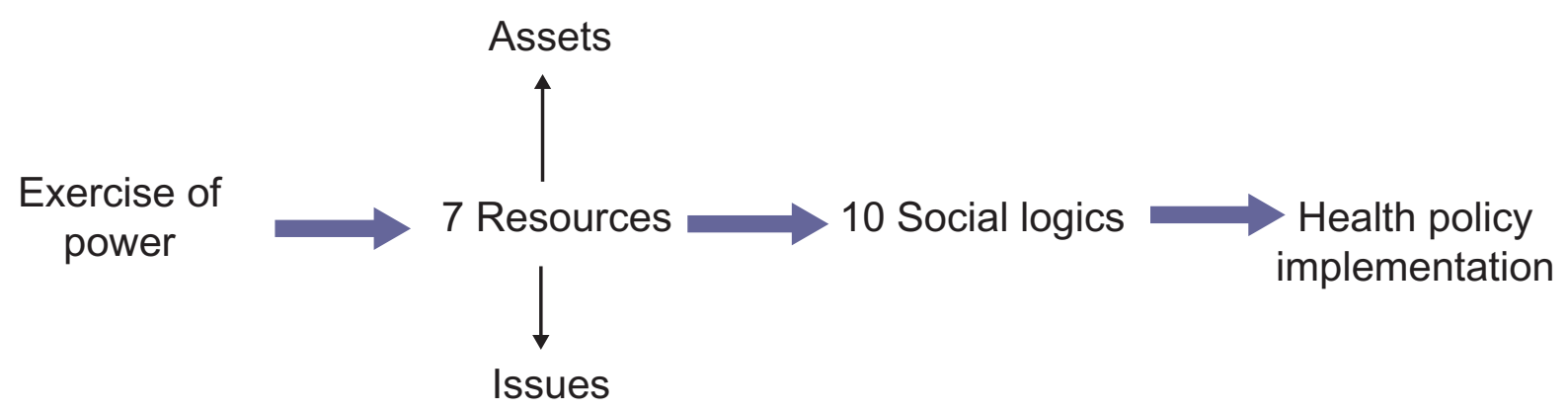

Figure 3 Power, actors and social logics.

Finally, this approach allowed us to build a conceptual framework (Figure 4) ${ }^{34}$ that integrates several theoretical approaches. Only a plurality of different theoretical, conceptual, and methodological approaches allows us to account for these actors' reasoning, embedded in the exercise of power: development anthropology, the study of public policies and the sociology of organization.

\section{Sampling and study population}

Yin advises that "the samples of each method may be nested within that of the other". Thus, we specify here how we chose the case study used in this research and how we selected certain individuals to participate as sources of data.

For obvious reasons of time and resource constraints, we chose to carry out a simple case study with embedded levels of analysis..$^{45}$ The case study is of an international non-governmental organization project that is implementing the health policy with the support of a District Health Team. The case was selected in collaboration with Ministry officials. The choice was based on the case's potential for enhancing comprehension of the problem under study. Subsequently, categories of actors were defined within this case to orient data collection.

The selection of actors to be involved in the analysis rested also on the conceptual integration, on one hand, of development anthropology's notion of strategic groups ${ }^{42}$ and, on the other, of scholars involved in public policies. ${ }^{38}$ The idea of strategic groups, used since the 1950s by Sayles, according to Crozier and Friedberg, ${ }^{43}$ is seen as a working hypothesis for researchers. These groups were

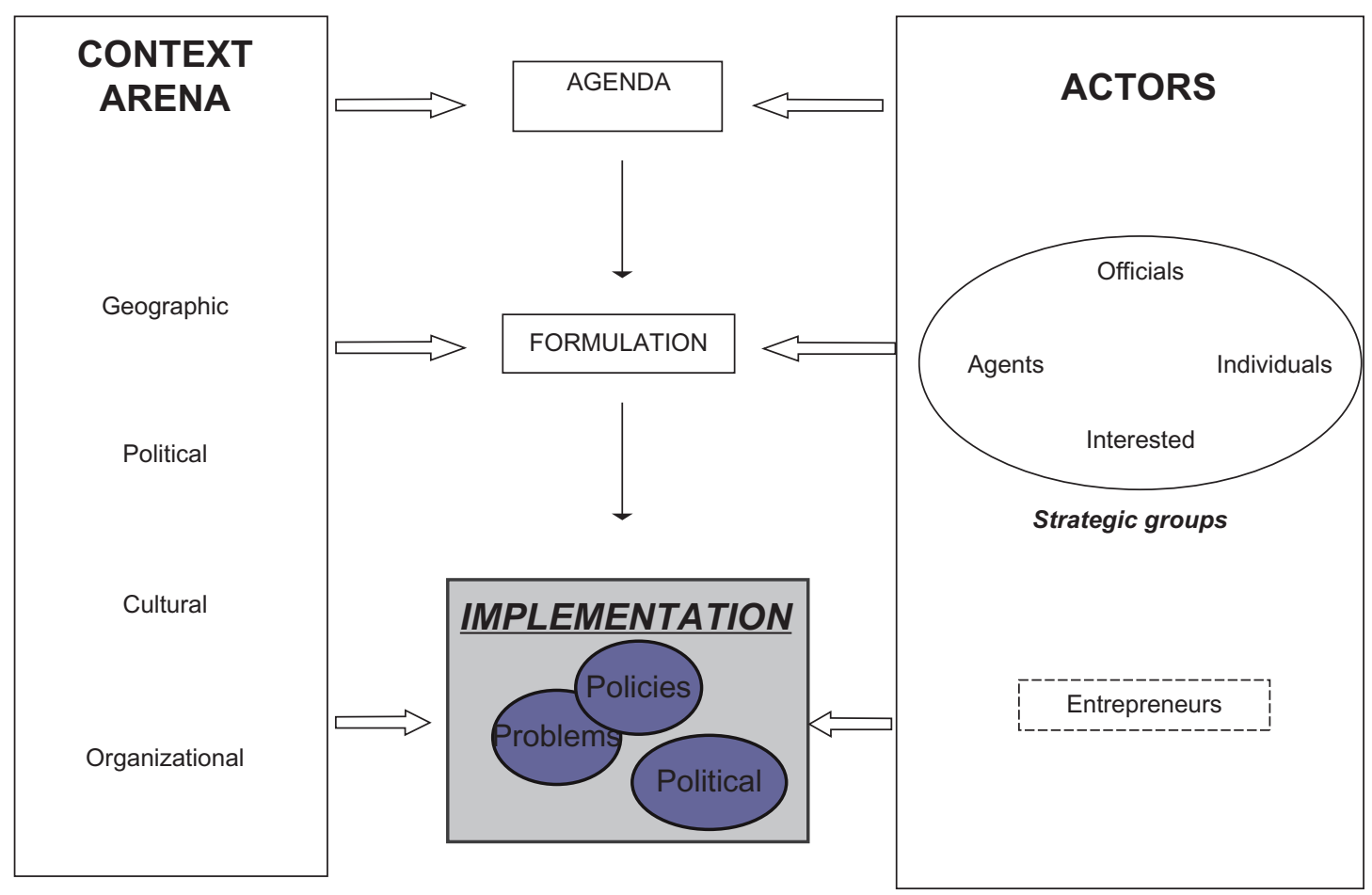

Figure 4 Integrated analytical framework. 
empirically constructed in line with Lemieux's typology, with the addition of Kingdon's distinction between actors working within the government apparatus and those outside it, depending on whether they are specialists or not in the matter being addressed by the policy. Thus, we identified four groups of actors, as described in Table 1 applied to this case study.

\section{Tools and data collection; and data analysis}

In the present study, the tools we used were mostly, but not entirely, qualitative (which allows us to speak about qualitative/quantitative integration). We mentioned earlier, the value of using several different instruments to respond to a single question - in this case, the notion of equity. In this section, we wish to highlight an innovation, which is the use of a data collection technique largely incorporated into what is today referred to as the mixed methods approach. ${ }^{22}$

We used concept mapping as a research method for understanding local views of equity among two of the four groups of actors; (1) interested parties: members of the community management committees; and (2) agents: nurse managers concerned with the health policy under consideration. While this technique (qualitative and quantitative) has been used in North America and elsewhere, to our knowledge it has not yet been applied in Africa in any vernacular language. We consider concept mapping to be the epitome of mixed methods because this technique collects both qualitative and quantitative data and enables both qualitative and quantitative analyses during the process. The technique is made up of four successive steps, which are detailed in another publication. ${ }^{46}$ The application of concept mapping in this particular context raises many issues and presents certain methodological limitations that are beyond the scope of this paper. We elected to use it because of its relevance, not so much to statistical analysis, but to the process of producing and validating results. It is the entire process, not only the statistical analyses, that is relevant, and particularly the graphical representation that it makes possible. This rigorous process produces results that make sense for the participants because their validation of the analyses is predominant. Producing data that the participants consider to be valid, without sacrificing the rigor of the statistical analysis, is thus the central criterion of relevance for this methodological choice. Still, data analysis is not limited to those moments when we are dealing directly with the participants. Of course, the validation of the participants is essential, but the researcher must also carry out an analysis. The integration of quantitative and qualitative analyses (in the form of content and theme analysis) is also continuous. Thus, we produced six different tools from concept mapping that allowed us to comprehend the meaning of the term "social justice": 1) the list of statements; 2) the list of clusters with their individual and collective labels (derived by consensus); 3) a map of the statements; 4) a map of the clusters; 5) a map of the statements by level of importance; and 6) a map of the clusters by level of importance.

\section{Knowledge dissemination and utilization}

The specific nature of public health research is that many of its researchers work to ensure outcomes that are useful and are used for interventions. Utilization (except process use) can take many forms: conceptual, symbolic, and instrumental..$^{47}$ For the purposes of this article, which aims to show that many sources can be used at different steps in the research process, we are interested primarily in instrumental utilization.

While dissemination should not be confused with utilization, we organized a classic process of knowledge sharing, from dissemination activities to a probable utilization outcome. Communications were carried out in national and international conferences, and scientific articles were published. These activities will ultimately have effects on the conceptual utilization of the study results. In Burkina Faso, presentations to students in the faculty of medicine, political decision-makers and researchers have helped to remind them of the importance of ensuring greater equity of access

Table I Groups of actors in the implementation of health policy

\begin{tabular}{llll}
\hline $\begin{array}{l}\text { Position in relation to } \\
\text { government apparatus }\end{array}$ & Definitions & Characteristics & Actors involved \\
\hline IN & Officials & Not specialized politicians & Deputies, consultants, experts \\
& Agents & Specialized bureaucrats & Nurses, physician \\
OUT & Individuals & Not specialized voters, & Cultivators, worst-off, users (and nonusers) \\
& & patients services & NGO member, health management \\
& Interested & Specialized experts & committee team member, Health drug \\
& & & depot manager \\
\end{tabular}


to the health care system. This, however, was not enough; one conclusion of this study was the urgent need for action research to study community exemption mechanisms for indigents (who are not able to pay for health care), not only to produce knowledge that will lead to action at the local level, but also to influence the behavior of the social actors. ${ }^{34}$ Thus, between 2004/2005 (writing and defense of the thesis) and 2007 (start of the action research), four major steps made the realization of this doctoral ambition possible.

In a first step, we took advantage of a workshop on the theme of knowledge transfer organized by the Canadian Coalition for Global Health Research in July 2004 in Canada, to develop, with a researcher from Burkina Faso, the broad lines of this action research. Then, we knew that "research is more likely to inform policies and programs when there is a three-way process of communication among researchers, decision-makers and communities". ${ }^{48}$ The active participation of everyone involved (health officials, community leaders) in decisions taken by the authorities is also an essential strategy for their implementation. ${ }^{49}$ This is why, in a second step, two workshops were organized in Burkina Faso in March 2005. These workshops made it possible to present and discuss the results of this study and, at the same time, to develop the protocol for the action research in a participatory manner. Then a student (a Burkinabé physician) in the Master's in Community Health program at Université Laval (Canada) carried out a feasibility study on the action in August 2005. This third step helped us to better understand, at a preliminary stage, how the actors perceived the action's contextual relevance (responsiveness) and potential for success. Finally, in a fourth step, the co-investigators met in November 2005 in Burkina Faso to finalize the draft of the protocol, plan activities, prepare tools for data collection and verify again the interest among decision-makers for such a process. The Ministry of Health supported this study.

Three primary, tangible effects should be retained from this whole process. The first is that this action research was able to start in September 2007, for a period of 3 years. The second is that, based on these efforts, two other studies were started in early 2008 on user fees exemption for the worstoff and on the criteria and processes for selecting these. Finally, the third, unintended, outcome is an example of the appropriation of this process by officials of the Ministry of Health. Thus, we observed that, in formulating a recent public policy on access to emergency obstetrical care, ${ }^{50}$ the authorities decided to make these services free-of-charge to indigent women. To select these women, they proposed to implement a process that resembles, in every respect, our action research protocol.

\section{Discussion}

The methodological limitation of this a posteriori reflective exercise is, precisely, that it was carried out after the research process. Clearly, we were unable to foresee at the start of this doctoral thesis that it would contribute to the reflection on methodological pluralism. It was in the experience of finding appropriate methods, good concepts, and theoretical approaches to respond to the core research question on equity and the implementation gap that we turned to pluralism. This manifests "the opportunistic nature of mixed-method design". ${ }^{31}$ Thus, this is not so much an exemplary case, but rather one that illuminates the "methodological polytheism" of Bourdieu raised by Wacquant, in which "the palette of methods used is aligned with the problem being treated and is the subject of reflection in the same action where it is used to resolve a specific question". ${ }^{51}$ Given the complexity of the subject being addressed in this public health study, we had no other choice but to resort to pluralism throughout the research process. Clearly, the degree of plurality varied from one step to another (Table 2), and we do not suggest that the level of plurality should be at the maximum at all times and in all steps of all public health studies. Yin ${ }^{27}$ asserts that "the more that two (or more!) methods have been integrated into each of the procedures, the stronger the 'mix' of methods". While Yin was not always clear on what he meant by methods, if we use this term in its broadest sense, the present article shows that we have tried to be as integrative as possible and to use pluralism at every step. This integrative process is summarized in Table 2.

This type of reflective exercise remains rare, ${ }^{c}$ and we do not claim to have exhausted the analysis in this article. Nevertheless, we believe we have demonstrated some important elements, although, at the same time, this analysis raises several points.

While most of the data used in this study were qualitative (QUAL), quantitative information (QUANT) was not set aside. Thus, taking up again Creswell's and Clark's ${ }^{16}$ typology, we used an embedded design in which QUANT provided a supportive, secondary role in the study based primarily on QUAL, which we can summarize as QUAL(quant). In the vocabulary of Johnson et $\mathrm{al}^{25}$ this therefore constituted a qualitative-dominant design. In the present case, anchored in

'One exception is the excellent analysis of interaction between a PhD student and the student's supervisor. ${ }^{52}$ 
Table 2 Integration and pluralism at every step of a public health study

\begin{tabular}{|c|c|c|}
\hline Steps & Type of pluralism/mixing & Burkina Faso case study \\
\hline \multirow[t]{2}{*}{ Research questions } & Multiple methods for a single question & $\begin{array}{l}\text { Concept of equity: concept mapping, in-depth } \\
\text { interviews, focus groups, etc. }\end{array}$ \\
\hline & One method for several questions & Participant observation: all research questions \\
\hline $\begin{array}{l}\text { Conceptual framework and } \\
\text { theoretical approach }\end{array}$ & Multiple disciplines & $\begin{array}{l}\text { Stream theory of political science; development } \\
\text { anthropology; sociology of organization }\end{array}$ \\
\hline Sampling & $\begin{array}{l}\text { Samples for each method may be } \\
\text { nested within those of the others }\end{array}$ & $\begin{array}{l}\text { Embedded single case study and selection of } \\
\text { strategic actors }\end{array}$ \\
\hline Tools and data collection & Qualitative and quantitative & Mostly qualitative and a mixed methods \\
\hline Data analysis & & technique (concept mapping) \\
\hline $\begin{array}{l}\text { Knowledge dissemination } \\
\text { and utilization }\end{array}$ & $\begin{array}{l}\text { Different types of utilization and } \\
\text { multiple strategies }\end{array}$ & $\begin{array}{l}\text { Mostly instrumental utilization, with multiple } \\
\text { strategies, leading to the conduct of several } \\
\text { operational studies }\end{array}$ \\
\hline
\end{tabular}

a constructivist paradigm and influenced by anthropology, we could have refused from the outset to use quantitative data and an analytical framework that integrated several disciplines to circumscribe the subject being studied. However, we did not; we used pluralism at every step of the process, and not just in terms of the type of data (QUAL vs QUANT). This embedded design summarizes the holistic perspective of our research process. Looking back now on the techniques we used, we consider concept mapping to be the ultimate mixed method. Indeed, this one technique employs both QUAL and QUANT not as two separate techniques, but as a single technique. What's more, this technique allows us to carry out both QUAL (eg, content analysis) and QUANT (eg, multidimensional scaling) analyses and interpretations.

At the end of this case study, we suggest that public health researchers can no longer afford to stint on methodological pluralism, and not just in terms of qualitative and quantitative data (as we have seen), if they are to improve on "the 'goodness' of their answers". ${ }^{33}$ Presentation of this case study could surely inspire some novices and ultimately be used in teaching to show it is possible to use methodological pluralism in doctoral research, in addition to the use of qualitative and quantitative data. Nevertheless, while possible, this is not always easy in the current academic context in public health.

Even taking into account the circumstances of a doctoral thesis, we believe pluralism can also be applied to these types of studies within a single study. While the academic system and supervisors, often constrain students to focus and limit the subjects and methods of their doctoral research, we believe this can be detrimental to the understanding of the complex phenomena we study on public health. Academic training in research is not very supportive of interdisciplinarity and pluralism. In addition, "we are raising a generation of scholars, many of whom do not know what a standard deviation is, on the one hand, or what a constant comparative analysis is, on the other". ${ }^{33}$ Much work remains to be done as, for example, one Canadian biomedical scientist (member of peer review committees at the Canadian Institutes of Health Research) explained that "A qualitative evaluation is an evaluation balanced by perception with control conditions, distribution curves, statistics, and the like". ${ }^{53}$ This is why some have recommended the creation of specific courses on mixed methods. ${ }^{54}$ As far as we know, in Canada there is just one university (McGill) that began offering, in 2009, the first graduate course in health sciences on mixed methods research. Nevertheless, recent research in Canada shows that for biomedical scientists, "exposure to social science research through professional experience may also play a significant role in fostering better educated and more positive opinions toward the social sciences". ${ }^{53}$ Certain researchers in public health have been seeking solutions to this for some time because "this barrier will grow in magnitude since many of the advances in knowledge today occur from the integration of the knowledge and skills of different disciplines". ${ }^{55}$ The growing complexity of the subjects being studied in public health, in such field studies, should certainly push these boundaries. In fact, the knowledge being produced is more type 2 than type 1 . In type 1 , the knowledge is produced by a single discipline, within a perspective that is essentially cognitive and homogeneous, whereas type 2 has to do with broader, transdisciplinary knowledge in a context of application and social distribution. ${ }^{56}$ Moving to a model of knowledge production that is type 2 rather than type 1 also requires institutional change in how researchers are trained and therefore in how academic institutions function. There is still much to do in the field of public health to ensure that students do not drown in statistics courses, that are interdisciplinary, and that systems are put in place so that knowledge produced is both usable and used. We have raised this question elsewhere in the context of global health research. ${ }^{57}$ 
Going back to issues associated with methodological pluralism in a single study, this case study raises more questions than answers. It seems possible, even desirable, to use pluralism throughout the public health research process - but to what extent? At least, as pointed out in the Introduction, this paper shows it was possible within a study anchored in a constructivist paradigm. Given the pragmatism of defenders of mixed methods,${ }^{58}$ can they really reconcile two different visions of the world that are often considered incommensurable? Is "paradigmatic pluralism" ${ }^{17}$ possible? We may wonder, since "the objective pursued by crossdisciplinary collaboration therefore first requires a common framework of understanding (with structural and methodological equivalence)". ${ }^{7}$ Moses and Knutsen ${ }^{18}$ distinguish methodological pluralism from scientific realism, in that it does not search for synthesis, nor does it attempt to create a new hegemonic vision of science. Instead, methodological pluralism accepts the inherent tensions between naturalism and constructivism, while recognizing that certain methods, even if they originate from different methodologies, may be more appropriate for some research questions than for others. It is not only, nor the same as, simply mixing qualitative and quantitative data. Constructivists could use and interpret quantitative data, as this case study demonstrates. But is it possible, at the heart of a single study, to use theories, concepts and methods derived from two different manners of thinking? An analysis of several single studies employing methodological pluralism under various epistemological perspectives could provide answers to this question.

\section{Conclusion}

We believe this case study demonstrates methodological pluralism, which goes beyond the use of qualitative and quantitative data, is not only necessary for public health research, but feasible within the context of a doctoral study. Nevertheless, the academic obstacles to such pluralistic and interdisciplinary practices remain significant. Teaching in public health is still very compartmentalized (as is research funding) and still much influenced by epidemiology and statistics. ${ }^{57}$ The strengthening of interdisciplinary and pluralist research is becoming a necessity. One option that should certainly be pursued very soon is the creation of graduate courses on mixed methods, and it is our hope this article will serve as a case study to this end. This is indispensable because public health today is probably anchored in what Kesteman ${ }^{59}$ calls a "new scientific culture [that] must find practical solutions to complex problems, create new knowledge in a context of urgency, and take into account multiple and often contradictory perspectives".

\section{Acknowledgments/disclosure}

The authors report no conflicts of interest in this work. This paper was first presented at a Methodological Pluralism Workshop in Rennes (France), Joint Sessions of the European Consortium for Political Research, April 12-16, 2008. We would like to thank all those who commented on this paper on that occasion. We also thank Catherine Pirkle for support provided for the literature review. This research was made possible through funding in 2003 from the International Development Research Centre (IDRC) in Canada. V. Ridde is currently a Canadian Institutes for Health Research (CIHR) New Investigator. Thanks to Donna Riley for translation and editing support.

\section{References}

1. Schwartz S, Carpenter KD. The right answer for the wrong question: consequences of type III error for pubic health research. Am J Public Health. 1999;89(8):1175-1180.

2. Granger GG. La Science et les Sciences. 1re éd. Paris, France: Presses universitaires de France; 1993.

3. Weber M. Le savant et le politique. Paris, France: Plon 10/18; 1963.

4. Ridde V. Reducing social inequalities in health: public health, community health or health promotion? Promotion and Education. 2007;XIV(2):63-67.

5. Fournier P. L'art et la science de la santé publique. In: Gérin M, Gosselin P, Cordier S, Viau C, Quénel P, Dewailly E, editors. Environnement et santé publique: fondements et pratiques. [St-Hyacinthe, Québec], [Paris, France]: Edisem ; Diffusion Éditions Tec and Doc; 2003:39-57.

6. Fassin D. Faire de la santé publique. Rennes: Editions de l'ENSP; 2005.

7. Jacob S. Cross-Disciplinarization: A New Talisman for Evaluation ? Americal Journal of Evaluation. 2008;29(2):175-194.

8. Levin-Rozalis M. Evaluation and research, differences and similarities. Canadian Journal of Program Evaluation. 2003;18(2):1-31.

9. Rosen G. A History of Public Health. Expanded ed. Baltimore, MD: Johns Hopkins University Press; 1993.

10. Detels R. Oxford Textbook of Public Health. 4th ed. Oxford, UK: Oxford University Press; 2002.

11. McKinlay JB, Marceau LD. To boldly go. Am J Public Health. 2000; 90(1):25-33.

12. Lock M, Nguyen V-K, Zarowsky C. Global and Local Perspectives on Population Health. In: Heymann J, Hertzman C, Barer ML, Evans RG, editors. Healthier Societies. From Analysis to Action New York, NY: Oxford University Press; 2005:58-82.

13. Ridde V, Delormier T, Gaudreau L. Evaluation of Empowerment and Effectiveness: Universal Concepts ? In: McQueen DV, Jones CM, editors. Global Perspectives on Health Promotion Effectiveness. Volume I New York, NY: Springer Science and Business Media; 2007:389-403.

14. Morin E. Introduction à la pensée complexe. Nouv. ed. Paris, France: Seuil; 2005.

15. Callon M, Lascoumes P, Barthe Y. Agir Dans un monde Incertain: Essai sur la démocratie technique. Paris, France: Seuil; 2001.

16. Creswell JW, Plano Clark VL. Designing and Conducting Mixed Methods Research. Thousand Oaks, CA: SAGE Publications; 2007.

17. Greene JC. Mixed Methods in Social Inquiry. San Francisco: Wiley; 2007.

18. Moses JW, Knutsen TL. Ways of Knowing: Competing methodologies in social and political research. Houndsmills, UK: Palgrave Macmillan; 2007.

19. Maton K, Perkins D, Saegert S. Community psychology at the crossroads: Prospects for interdisciplinary research. Am J Community Psychol. 2006;38(1-2):9-21. 
20. Patton MQ. Creative evaluation. 2nd ed. Newbury Park, CA: Sage Publications; 1987.

21. Creswell J, Plano Clark V, Gutmann M, Hanson W. Advanced mixed methods research designs. In: Teddlie TC, editor. Handbook of Mixed Methods in Social and Behavioral Research. Thousand Oaks, CA: Sage Publications; 2003:209-240.

22. Pluye P, Nadeau L, Gagnon M-P, Grad R, Johnson-Lafleur J, Griffiths F. Les méthodes mixtes pour l'évaluation des programmes. In: Ridde $\mathrm{V}$, Dagenais C, editors. Concepts et pratiques de l'évaluation de programme. Manuel d'enseignement. Montréal, Canada: Presses de l'Université de Montréal; in press.

23. Baker C, Norton S, Young P, Ward S. An exploration of methodological pluralism in nursing research. Res Nurs Health. 1998;21(6): 545-555.

24. Kaplan B. Evaluating informatics applications - some alternative approaches: theory, social interactionism, and call for methodological pluralism. Int J Med Inform. 2001;64(1):39-56.

25. Johnson RB, Onwuegbuzie AJ, Turner LA. Toward a definition of mixed methods research. J Mix Methods Res. 2007;1(2):112-133.

26. Morse JM, Chung SE. Toward holism: The significance of methodological pluralism. International Journal of Qualitative Methods, 2 (3). Article 2. Retrieved Feb. 23, 2008 from http://www.ualberta.ca/iiqm/ backissues/2_3final/pdf.morsechung.pdf. 2008;2003(3).

27. Yin RK. Mixed methods research: are the methods genuinely integrated or merely parallel? Res $S$ ch. 2006;13(1):41-47.

28. Barker C, Pistrang N. Quality criteria under methodological pluralism: implications for conducting and evaluating research. Am J Community Psychol. 2005;35(3-4):201-212.

29. Yin R. Mixed methods research: are methods genuinely integrated or merely parallel?. Res Sch. 2006;13(1):41-47.

30. Miles MB, Huberman AM. Qualitative Data Analysis : an expanded sourcebook. 2nd ed. Thousand Oaks, CA: Sage Publications; 1994.

31. Teddlie C, Tashakkori A. A general typology of research designs featuring mixed methods. Res Sch. 2006;13(1):12-28.

32. Teddlie C, Tashakkori A. Major issues and controversies in the use of mixed methods in the social sciences and behavioral sciences. In: Tashakkori A, Teddlie C, editors. Handbook of Mixed Methods in Social and Behavioral Research. Thousand Oaks, CA: Sage Publications; 2003.

33. Tashakkori A, Teddlie C. Handbook of Mixed Methods in Social and Behavioral Research. Thousand Oaks, CA: SAGE Publications; 2003.

34. Ridde V. "The problem of the worst-off is dealt with after all other issues": The equity and health policy implementation gap in Burkina Faso. Soc Sci Med. 2008;66:1368-1378.

35. Kingdon JW. Agendas, Alternatives and Publics Policies. 2nd ed. New York, NY: Harper Collins; 1995.

36. Rochefort DA, Cobb RW. Problem definition: an emerging perspective. In: Rochefort DA, Cobb RW, editors. The Politics of Problem Definition: Shaping the policy agenda. Lawrence, KS: University Press of Kansas; 1994:1-31.

37. Saetren H. Facts and myths about research on public policy implementation: out-of-fashion, allegedly dead, but still very much alive and relevant. Policy Stud J. 2005;33(4):559-582.

38. Lemieux V. L'étude des politiques publiques, les acteurs et leur pouvoir 2ème ed. Québec, Canada: Les Presses de l’Université Laval; 2002.
39. Zahariadis N. Ambiguity, Times and Multiple Streams. In: Sabatier PA, editor. Theories of the Policy Process. Theoretical lenses on public policy. Boulder, CO: Westview Press; 1999:73-93.

40. Pülzi H, Treib O. Implementing Public Policy In: Fischer F, Gerald J. Miller GJ, Sidney MS, editors. Handbook of Public Policy Analysis. Theory, Politics, and Methods. Baton Rouge, LA: CRC Press; 2006.

41. Demers L, Lemieux V. La politique québécoise de désengorgement des urgences. Can Public Adm. 1998;41(4):501-528.

42. Olivier de Sardan J-P. Anthropology and Development. Understanding Contemporary Social Change. London, UK: Zed Books; 2005.

43. Crozier M, Friedberg E. L'acteur et le système. Paris, France: Éditions du Seuil; 1977.

44. Pressman JL, Wildavsky A. Implementation. How great expectations in Washington are dashed in Oakland. 3rd ed. Berkeley, CA: University of California Press; 1984.

45. Yin RK. Case Study Research: Design and methods. Vol 5. 2nd ed. London, UK: Sage Publications; 1994.

46. Ridde V. Equity and health policy in Africa: using concept mapping in Moore (Burkina Faso). BMC Health Serv Res. 2008;8:90.

47. Cousins JB. Commentary: Minimizing evaluation misuse as principled practice. Am J Eval. 2004;25(3):391-397.

48. Porter J, Prysor-Jones S. Making a Difference to Policies and Programs: A Guide for Researchers. Washington, DC: SARA; 1997.

49. Krull W. Editorial: helping to create symmetric partnerships: a new approach to supporting research in Sub-Saharan Africa. Trop Med Int Health. 2005;10(2):118-120.

50. Ministère de la santé. Stratégie nationale de subvention des SONU. Ouagadougou: DSF; 2006.

51. Bourdieu P. Science de la science et réflexivité. Paris, France: Raisons d'agir; 2001.

52. Li S, Seale C. Learning to do qualitative data analysis: an observational study of doctoral work. Qual Health Res. 2007;17(10): 1442-1452.

53. Albert M, Laberge S, Hodges BD, Regehr G, Lingard L. Biomedical scientists' perception of the social sciences in health research. Soc Sci Med. 2008;66(12):2520-2531.

54. Tashakkori A, Teddlie C. Issues and dilemmas in teaching research methods courses in social and behavioural sciences: US perspective. International Journal of Social Research Methodology. 2003;6(1):61-77.

55. Dean K, Hunter D. New directions for health: towards a knowledge base for pubic health action. Soc Sci Med. 1996;42(5): 745-750.

56. Gibbons M, Limoges C, Nowotny H, Schwartzman S, Scott P, Trow M. The New Production of Knowledge. The dynamics of science and research in contemporary societies. London, UK: Sage Publications; 1994.

57. Ridde V, Mohindra K, LaBossière F. Driving the global public health research agenda forward by promoting the participation of students and new researchers: Perspectives from Quebec. Can J Public Health. 2008:460-465.

58. Johnson RB, Onwuegbuzie AJ. Mixed methods research: A research paradigm whose time has come. Educational Researcher. 2004; 33(7):14-26.

59. Kesteman J-P. L'un, le multiple et le complexe. L'Université et la transdisciplinarité. A Contrario. 2004;2(1):89-108.
Research and Reports in Tropical Medicine

\section{Publish your work in this journal}

Research and Reports in Tropical Medicine is an international, peerreviewed, open access journal publishing original research, case reports, editorials, reviews and commentaries on all areas of tropical medicine, including: Diseases and medicine in tropical regions; Entomology; Epidemiology; Health economics issues; Infectious disease; Laboratory

\section{Dovepress}

science and new technology in tropical medicine; Parasitology; Public health medicine/health care policy in tropical regions; and Microbiology. The manuscript management system is completely online and includes a very quick and fair peer-review system. Visit http://www.dovepress. com/testimonials.php to read real quotes from published authors. 